\title{
(C) OPEN ACCESS \\ Development of a portable blood salvage and autotransfusion technology to enhance survivability of personnel requiring major medical interventions in austere or military environments
}

\author{
Terence Gourlay, C Simpson, C A Robertson
}

\section{Biomedical Engineering, University of Strathclyde, Glasgow, UK}

Correspondence to Professor Terence Gourlay, Biomedical Engineering, University of Strathclyde, Glasgow, UK; terence.gourlay@ strath.ac.uk

Received 27 February 2017 Revised 21 July 2017 Accepted 26 July 2017 Published Online First 26 October 2017
Check for updates

To cite: Gourlay T, Simpson C, Robertson CA. J R Army Med Corps 2018;164:96-102.

\begin{abstract}
Introduction Uncontrolled haemorrhage is the leading cause of death on the battlefield, and two-thirds of these deaths result from non-compressible haemorrhage. Blood salvage and autotransfusion represent an alternative to conventional blood transfusion techniques for austere environments, potentially providing blood to the casualty at point of injury. The aim of this paper is to describe the design, development and initial proof-of-concept testing of a portable blood salvage and autotransfusion technology to enhance survivability of personnel requiring major medical interventions in austere or military environments.
\end{abstract}

Method A manually operable, dual-headed pump was developed that removes blood from site of injury to a collection reservoir (upper pump) and back to casualty (lower pump). Theoretical flow rate calculations determined pump configuration and a three-dimensionally printed peristaltic pump was manufactured. Flow rates were tested with fresh bovine blood under laboratory conditions representative of the predicted clinical environment.

Results Mathematical modelling suggested flow rates of $3.6 \mathrm{~L} / \mathrm{min}$ and $0.57 \mathrm{~L} / \mathrm{min}$ for upper and lower pumps. Using fresh bovine blood, flow rates produced were $2.67 \mathrm{~L} / \mathrm{min}$ and $0.43 \mathrm{~L} / \mathrm{min}$. To mimic expected battlefield conditions, upper suction pump flow rate was calculated using a blood/air mixture.

Conclusion The authors believe that this technology can potentially enhance survivability for casualties in austere and deployed military settings through autotransfusion and cell concentration. It reduces negative effects of blood donation on the conventional donor pool, and potentially negates the logistical constraints associated with allogenic transfusions.

\section{INTRODUCTION}

Uncontrolled haemorrhage is the leading cause of death on the battlefield, ${ }^{1}$ in which two-thirds of these deaths are a result of non-compressible (truncal) haemorrhage. ${ }^{2}$ In Iraq and Afghanistan, uncontrolled blood loss was the cause of death in $85 \%$ of the potentially survivable battlefield cases and in $80 \%$ of those who died in a military treatment facility. ${ }^{3}$ Between 2001 and 2011 in these conflicts, $25 \%$ of the 4596 combat deaths were potentially survivable, and $90 \%$ of the deaths occurred before the injured personnel reached a medical facility. Of the 4090 mortally wounded

\section{Key messages}

- Haemorrhage remains the most common cause of fatalities in military personnel under battlefield conditions.

- It is challenging to make adequate provision for blood replacement therapy using conventional means in the battlefield

- Autotransfusion, a common blood replacement technique in civilian settings, is not currently suited to the austere or deployed military environment.

- A novel autotransfusion system is described for use in austere settings, to follow the casualty journey from first contact, through evacuation and into the hospital setting.

- This device can be manually powered and is capable of handling up to $3 \mathrm{~L} / \mathrm{min}$ of blood, returning it directly back to casualty.

- The device promises to considerably reduce the mortality associated with major blood loss under battlefield conditions.

troops, 1391 died instantly and 2699 died before reaching a treatment facility; only 506 reached a hospital before succumbing to injury. These data highlight an obvious need for improving field treatment capability. ${ }^{4}$

Over $25 \%$ of military casualties require aggressive and urgent haemostatic resuscitation to increase survivability. ${ }^{5}$ Additionally, $30 \%-40 \%$ of these casualties that need blood transfusions when they reach emergency departments also suffer from acute traumatic coagulopathy (ATC) ${ }^{6-8}$ This is associated with an $80 \%$ mortality rate ${ }^{910}$ and is related to the resuscitation regime. Variations of blood transfusion techniques are possible, although very few blood restoration modalities are available to a field medic in austere conditions, due to blood provision and storage constraints. The urgent deployment of blood products (fresh frozen plasma and packed red blood cells) has been shown to attenuate ATC, although there are considerable logistical concerns and clinical risk with this type of intervention. ${ }^{11}$ As such, there is a need to develop innovative and less logistically intense mechanisms for treating casualties that require blood at point of injury.

Recent damage control resuscitation protocols have modified the ratios of blood elements 
administered to military casualties. ${ }^{12}$ These have signalled the necessary implementation of whole fresh warm blood (WFWB) administration in combat hospitals, where 'buddy transfusions' have exceeded 6000 units in recent combat operations. ${ }^{13}$ Although WFWB transfusions in the battlefield are feasible, and have been shown to aid effectiveness of clotting and oxygen transport, there is still potential for catastrophic outcomes such as haemolytic reactions. ${ }^{14}{ }^{15}$ Additional considerations include that donors are unable to provide more than a single unit, they require fluid therapy, they are limited to light duty for at least 72 hours following donation and are restricted from flying duties for this time period. ${ }^{16}{ }^{17}$ Military blood transfusions rely on donations from the general public and military personnel for treating massive blood loss in casualties. In 2013, 8000 blood components from UK donors were shipped overseas to combat zones, which required safe and sterile transportation over thousands of miles to military hospitals. Donated blood has been shown to increase death rates, accentuate bleeding, and it carries risk of biological reactions. ${ }^{18}$ Transfusion reactions are difficult to recognise in severely or multiply injured casualties. Haemolytic reactions present acutely with fever, dyspnoea and renal failure and delayed reactions may occur. ${ }^{19}$ To avoid these deleterious consequences, our proposed innovation allows the patient's own blood to be collected and recycled, a process known as autotransfusion.

Our group has previously developed an autotransfusion device for blood cell salvage in non-military clinical applications. ${ }^{20}$ HemoSep (Brightwake, Nottingham, UK) is a portable intraoperative blood salvage device that achieves effective blood recycling. It concentrates the residual blood during and after an operative procedure, returning all cell species including platelets, red and white blood cells, and proteins and clotting residuals back to the patient. This technology has been successfully and broadly used in a wide range of applications. ${ }^{21}$ It is capable of reducing blood loss in cardiac and other types of 'clean site' procedures, including paediatric surgery. HemoSep's blood bag component uses a membrane-controlled superabsorber-driven plasma removal process which can preserve all cell species and remove contaminants prior to re-transfusion. The control membrane has a pore size that prevents migration of cellular species from the blood to the superabsorber, while allowing free passage of diluted plasma into the superabsorbent polymer. The separated cells are then returned to the patient by intravenous transfusion. HemoSep efficacy has been demonstrated clinically using residual diluted bypass and circuit blood. ${ }^{20}$ The use of the technology was also associated with reduced postoperative bleeding and red blood cell transfusion, as well as a decrease in postcardiac bypass inflammatory response. ${ }^{21}$

\section{Design considerations for the technology}

The proposed system consists of two peristaltic pumps, driven from a single drive shaft with independent activation. The primary pump provides the suction, removing blood from the wound site to a settlement reservoir. The secondary pump can be activated using a simple switch mechanism and returns blood to the casualty at a consistent flow rate of up to $500 \mathrm{~mL} / \mathrm{min}$ via an infusion line. This arrangement permits transfusion of blood intermittently to the casualty without interrupting the critical suction of blood from the wound site. In this way, constant autotransfusion can be carried out, controlling two pumps from one drive shaft. This thereby reduces the complexity of the technique insofar as only one drive crank needs to be used. Early autotransfusion may ensure efficient patient stabilisation to increase likelihood of survivability from the field to a medical facility. To maximise the impact and efficiency of the field-deployable autotransfusion system, the innovation comprises two primary technologies:

\section{Pump system}

This is a field-deployable military autotransfusion system which is lightweight, compact and manually operable. The core system would comprise a suction nozzle and tubing to evacuate blood from the wound site to a collection bag using a manually powered pump, and also incorporates a HemoSep haemoconcentration processing bag (for use where appropriate), low level anticoagulant-infused crystalloid fluid and a transfusion bag (Figure 1A):

- The collection bag receives blood from the wound via the pump; fluid suctioned from a wound site is a turbulent blood-air mixture. All air and major contaminants must

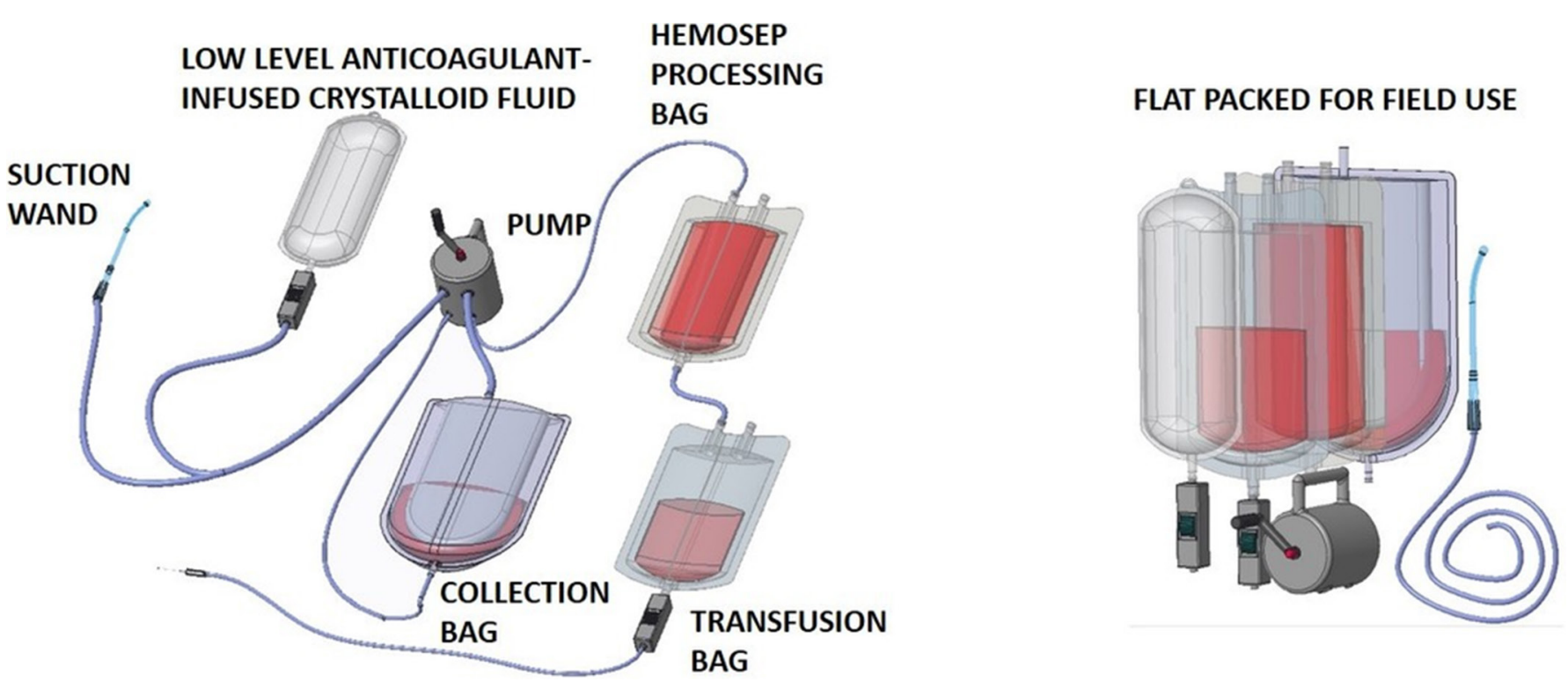

Figure 1 Design concept of the autotransfusion and cell concentration technology. The schematic of the blood salvage innovation (left), and as a flat-packed field-deployable kit (right). 
be removed before re-transfusion; the collection bag must perform these tasks efficiently without causing significant haemolysis. Where air intrusion into the system is unavoidable, this will ultimately be resolved by a settlement or air settlement reservoir.

- The HemoSep processing bag-not essential if autotransfusion is urgent to ensure patient stabilisation-can be easily and rapidly incorporated into the kit.

- The blood is finally deposited into a transfusion bag for subsequent re-transfusion.

- For field-deployability, the kit can be flat-packed (Figure 1B).

\section{Motorised docking station}

We aimed to develop a plug-and-play motor-driven docking station for the pump to allow autotransfusion and blood concentration in the military treatment facility. This would allow continual autotransfusion and blood concentration to ensure patient stabilisation. The autotransfusion process underpinning the development of the proposed technology and the design concept are shown in Figure 1.

\section{Pump configuration}

The system was designed as a single axle, independent double roller head, peristaltic pump mechanism, with two suctioning tubes capable of both constantly evacuating blood from the wound site and intermittently propelling this blood between the blood reservoir and the processing bag during use. The larger upper suction pump generates a vacuum to rapidly evacuate blood from the wound site via a manual hand-cranking peristaltic pump. A second pump positioned underneath (in its own chamber) will lie dormant until a mechanical latch is engaged that joins the axle from the first pump to the second. This will then rotate and cause the second pump to transport collected blood to the processing bag. The two pumps are connected to a common drive shaft, but operate independently using a latch system to activate the low flow system when required and to ensure that there is no interruption to blood evacuation during cell processing. This design was based on a conventional peristaltic roller mechanism, but in this case it has two roller heads, one capable of high flow (approximately $3 \mathrm{~L} / \mathrm{min}$ ) which is representative of a large bleed and one with a low flow configuration (approximately $0.5 \mathrm{~L} / \mathrm{min}$ ) to transfer concentrated blood from a collection reservoir to the processing bag or patient.

The high flow evacuation pump can be operated constantly and the activation of the low flow pump head does not interfere with its function. The drive shaft can be hand cranked using a handle on the upper aspect of the pump, with gearing enabling easy crank operation. The pump system must be capable of constantly extracting blood from the wound site while moving the blood into the collection bag or Hemosep bag and returning blood to the patient only when desired. The pump cylinder was designed as three separate interlocking sections; the first section contained a multiplier gearbox to increase output speed; the second (upper suction pump) section housed the high flow roller mechanism while the third (lower pump) contained the low flow rollers and latch mechanism allowing its activation/deactivation. The technology has in-built versatility. Under first contact conditions, the device may solely provide critical autotransfusion at point of injury and during transportation to immediately re-transfuse haemorrhaged blood. In the field hospital after casualty evacuation, where autotransfusion is non-urgent, this can be converted to a cell concentration device to return cell species (Figure 2).

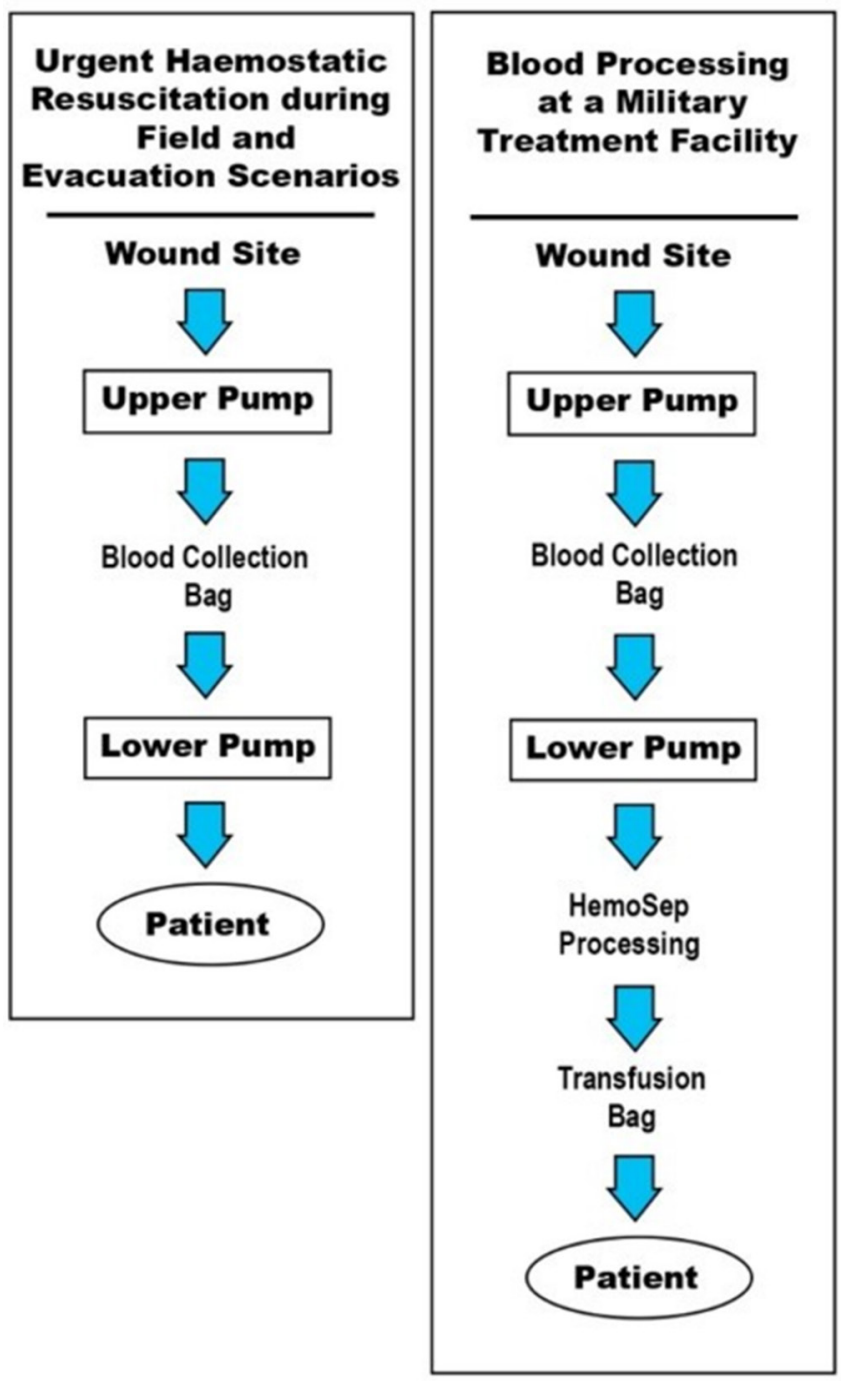

Figure 2 Flow chart of the autotransfusion and cell concentration processes. Under field and evacuation scenarios where haemorrhaged blood is immediately re-transfused (left) and at a military treatment facility where autotransfusion is non-urgent (right).

Tubing and pump specifications

Tubing and pump dimensions were based on initial concept ideas and design specification to create an ergonomic and portable pump. Pure platinum-cured silicone tubing was used for the upper pump (Watson-Marlow, Cornwall, UK) and lower pump (Cole Parmer, Hanwell, UK).

\section{Pump system}

Initial pump schematics were designed using Parametric Technology Corporation (PTC) Creo (PTC, Needham, Massachusetts, USA). The hardware, although complex, was designed for additive manufacturing techniques to ultimately enable the construction of lightweight components in a combination of aluminium and carbon fibre with a view to minimising the overall weight of the technology. For the pump prototype, all computer aided design (CAD) parts were three-dimensionally (3D) printed in aluminium (3D Alchemy, Sabre Software Development, Shropshire, UK), excluding gears (HPC gears, Derbyshire, UK) and shafts and rollers (upper suction pump rollers (diameter $30 \mathrm{~mm}$ and $30 \mathrm{~mm}$ height), lower pump rollers (diameter $30 \mathrm{~mm}$ and $15 \mathrm{~mm}$ height)) which were manufactured in-house in stainless 


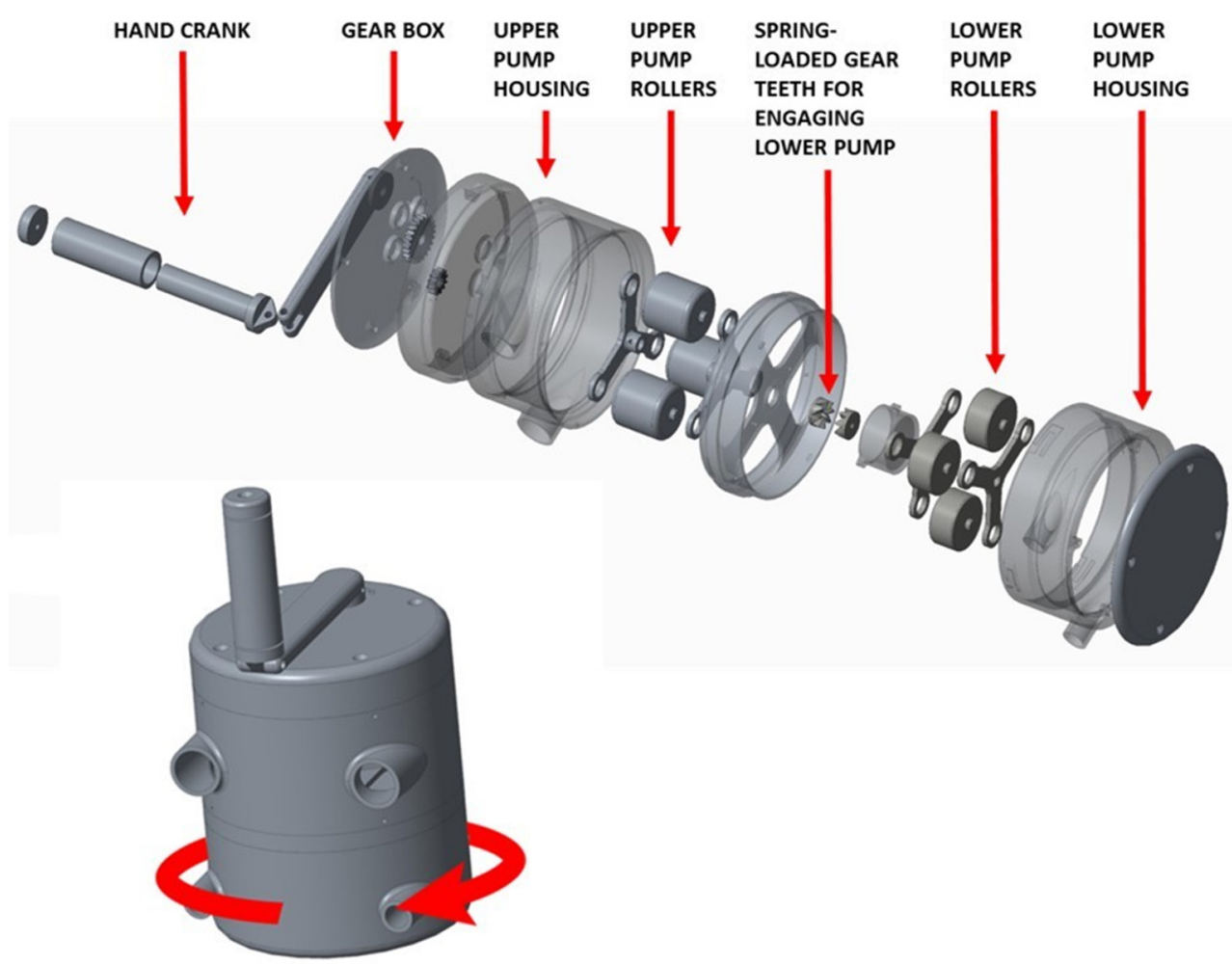

Figure 3 A computer aided design schematic of the pump mechanism. The spring-loaded lower compartment is manually twisted and locked in place to activate and deactivate when necessary.

steel. Roller supports were also 3D printed in stainless steel (3D Alchemy, Sabre Software Development, Shropshire, UK) (Figure 3). For urgent field use, the technology was designed with a removable handle and adapted for compatibility with an electronic screwdriver. This would give the user the opportunity to operate the pump at a high revolutions per minute (RPM) without any physical exertion, and this was included to enable continual use during the evacuation and transport phase of medical intervention. As part of the design process, modelling suggested that a pump with a 1:1 gear ratio would be incapable of achieving targeted flow rates. However, a 1:2 gearbox would attain flow rates of $3.6 \mathrm{~L} / \mathrm{min}$ and $0.57 \mathrm{~L} / \mathrm{min}$ for the upper and lower pumps, respectively, and this gearbox was selected.

\section{Motorised docking station development}

The plug-and-play motor-driven docking station for the pump was developed for use at a medical treatment facility. A direct current (DC) geared motor (24 V DC, 24 Nm, 125 RPM, Mellor Electric, RS Components, UK) was coupled (Ruland Aluminium Flexible Beam Coupling, RS Components, UK) with the pump and powered with a DC power supply (Digimess Concept Series, Digimess Instruments, Derby, UK) (Figure 4).

\section{Aims}

The overall objective of our research programme is to develop a technology fit for routine application by non-specialists in an operational setting, where cells harvested by this device are rapidly and directly transfused back into the casualty, and offers critical primary autotransfusion on the battlefield for haemorrhaging soldiers or in other austere settings. Crucially, the proposed technology represents a single, versatile treatment modality that accommodates all stages of medical intervention, from first contact, through casualty evacuation and transport, and ultimately for use in the military field hospital. The key elements in informing the design process for this new technology were; lightweight, ensuring ease of deployment in the battlefield; independence from mains power, enhancing the ability to deploy in the most challenging and austere settings; and a high flow capability, to enable blood salvage in the most severely injured casualty situations. The aim of this paper is to describe the key areas of activity involved in the design, development and feasibility testing of the technology (Box).

\section{METHODOLOGY}

Flow rate testing of the upper and lower pumps

The high flow pumping using the larger upper pump and low flow pumping capability of the smaller lower pump were tested

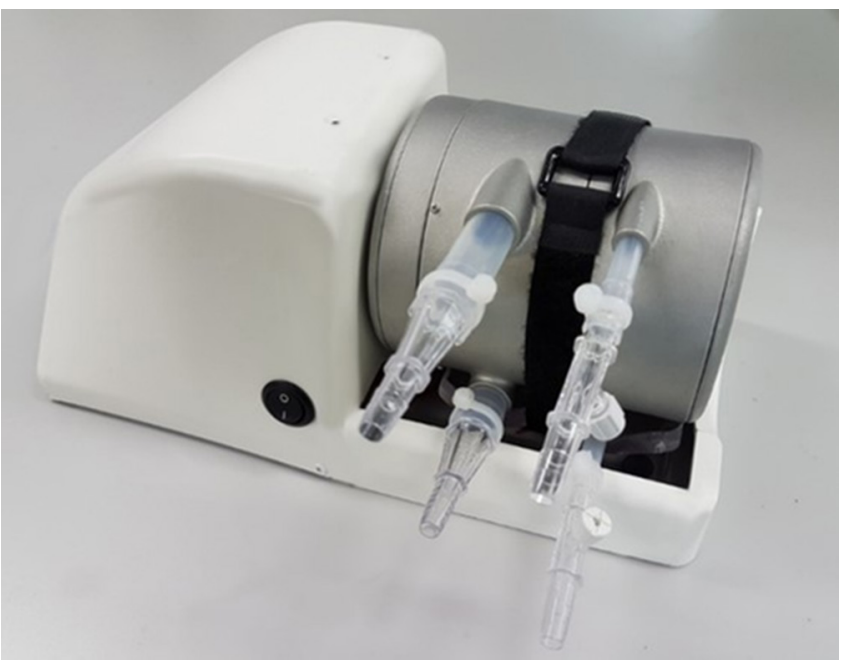

Figure 4 Plug-and-play motor-driven docking station for the manual pump to allow autotransfusion and blood concentration in a military treatment facility. 
Box The three main aims of the research that encompass the design, development and feasibility testing of the portable blood salvage and auto-transfusion technology are:

To design, develop and bench test an auto-transfusion system that would facilitate rapid re-transfusion of blood to the casualty without the HemoSep $®$ cell concentration cycle. This would permit rapid transfusion of whole blood to the casualty, reducing the processing time considerably.

- To develop a powered drive system that would permit the function of the auto-transfusion system over prolonged periods by a single user. This would reduce the number of personnel required to perform auto-transfusion and sustain the process period.

- To develop and bench test a 'base station' unit in order that the core system would be useable in the hospital setting as a HemoSep®/auto-transfusion system without the need for additional components. This system would have the effect of maximising the versatility of the system and broaden the availability of auto-transfusion throughout the patient journey.

using the motorised docking station (in order to control RPM input). The pump was tested using fresh bovine blood collected from a local abattoir (Sandyford Abattoir, Paisley, UK) in a sealed container and treated with 10000 IUs of heparin sodium from porcine mucosa (Sigma Aldrich, Dorset, UK) in $50 \mathrm{~mL}$ of $0.9 \%$ sodium chloride solution. Flow rates were set between 30 RPM and 75 RPM in accordance with realistic operational capabilities, and this was achieved by altering the voltage output of the power supply. For the upper and lower pumps, the inlet tubing was placed in a beaker containing $5 \mathrm{~L}$ and $2 \mathrm{~L}$ of blood, respectively, and the outlet tubing was placed in an empty beaker to measure volume of transferred blood. The flow rate was measured by calculating the time taken to transfer the blood through the pump-litres per minute was then subsequently calculated. Flow rate values were recorded at RPM values between 30 and 75 (Figure 5).

\section{Upper suction pump flow rate}

In real battlefield conditions, it would be anticipated that a mixture of blood and air would be suctioned during pump use, and as such, the flow rates under these conditions were also assessed. This was achieved by intermittently submerging the

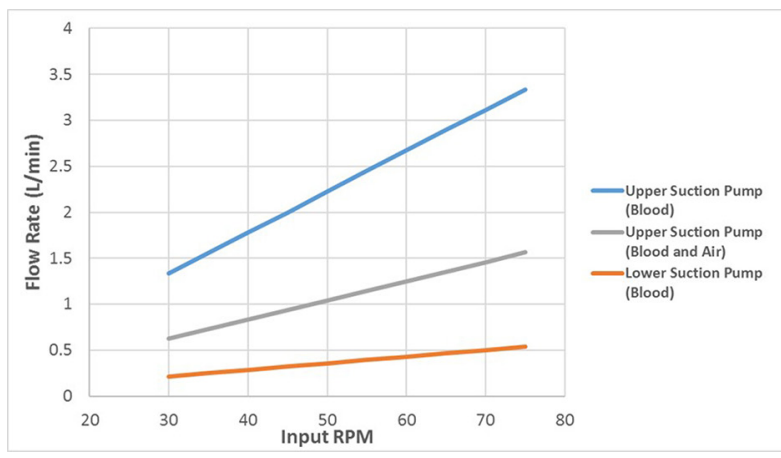

Figure 5 The flow rates for the upper and lower suction pumps over a range of values. The upper suction pump values were calculated with and without the presence of air. suction wand in the blood approximately every $2 \mathrm{~s}$ to collect both blood and air.

\section{Lower pump flow rate}

During pump deployment, blood is transferred from the collection bag to either the HemoSep processing or the transfusion bag-as such, no air enters this pump. The flow rate was measured by calculating the time taken to transfer $2 \mathrm{~L}$ of blood only through the pump and $\mathrm{L} / \mathrm{min}$ subsequently calculated.

\section{RESULTS}

\section{Upper suction pump flow rate}

Using blood and an input of $60 \mathrm{RPM}$, the evacuation and suction of $5 \mathrm{~L}$ of blood took $112 \mathrm{~s}$, and so $1 \mathrm{~L}$ of blood took $22.5 \mathrm{~s}$. Therefore, the upper suction pump for this input had a flow rate of $2.67 \mathrm{~L} / \mathrm{min}$ when using blood. Using a blood/air mixture the evacuation and suction of $5 \mathrm{~L}$ of blood took $240 \mathrm{~s}$, and so $1 \mathrm{~L}$ of blood took $48 \mathrm{~s}$. Therefore, the upper suction pump had a flow rate of $1.25 \mathrm{~L} / \mathrm{min}$ when using a blood/air mixture.

\section{Lower pump flow rate}

Using blood the evacuation and suction of $2 \mathrm{~L}$ of blood took $280 \mathrm{~s}$, and so $1 \mathrm{~L}$ of blood took $140 \mathrm{~s}$. Therefore, the upper suction pump had a flow rate of $0.43 \mathrm{~L} / \mathrm{min}$ when using blood.

The output flow rates obtained during test were slightly lower than the theoretical values calculated. This could be due to a number of reasons. First, timing started from when the pump was initially activated and there is a delay before blood enters the pump-this would account for a slight reduction in the output flow rate. Also, residual blood may remain in the tubing at the end of the test. Another possible reason for the lower output flow rates is that the roller inside the pump may not have fully occluded the tube-this could reduce pressure inside the pump and cause air to reside within the tubing. This would reduce the volume of blood inside the pump and as a result reduce the output flow rate.

\section{DISCUSSION}

The project primary objective was to develop a military version of the HemoSep device that is portable and can function independently of mains power (Figure 6). On reviewing the landscape of military recovery, this objective was considerably broadened to cover the entire journey and circumstances of the military casualty. The project produced a device that was versatile, having manual, portable power-driven and mains-driven derivative devices with a low haemolysis profile. This technology offers the potential to treat the casualty from the point of injury, through to the postsurgical period in their treatment pathway using one core technology. Injured military personnel require aggressive and urgent haemostatic resuscitation to increase survivability through the entire journey from the battlefield to the military hospital. Crucially, the proposed technology represents a single, versatile treatment modality that accommodates all stages of medical intervention (Figure 7). Since early intervention is crucial for haemorrhaging patients, our solution is a portable, efficient and rapid autotransfusion blood salvage device that recycles spilled blood at the point of injury-concentrating the residual blood and returning all cell species including platelets and red blood cells back to the patient.

The environment in which this technology will be deployed is a challenging one. In particular, the presence of complex contaminants in the forward military surgical setting is of concern. 


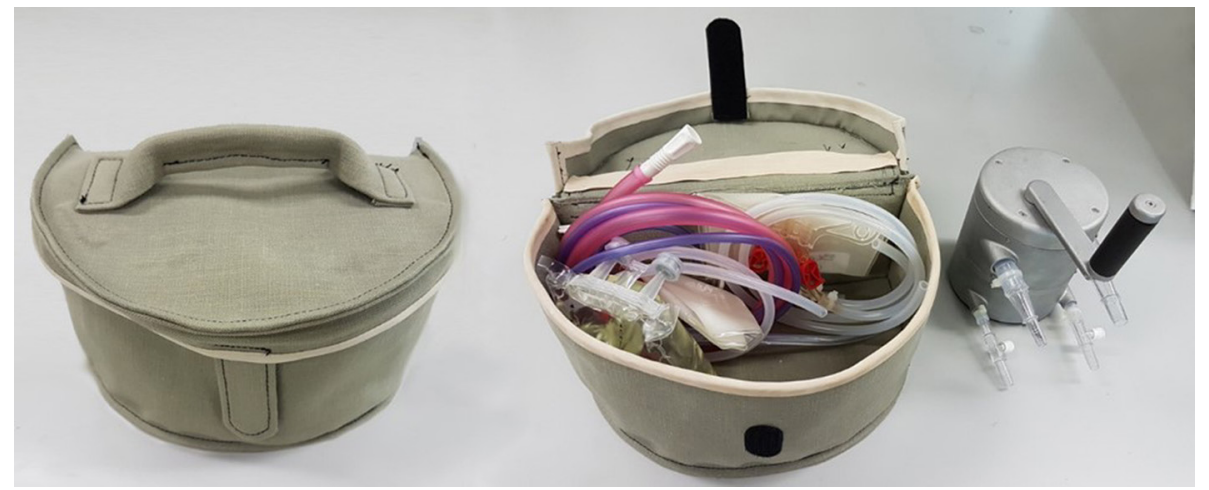

Figure 6 Left, the completed, field-deployable prototype in its closed bag and right, open with pump outside to display its contents.

Where these circumstances are recognised, the cell concentration element of the device should be deployed, supported by the inclusion of proprietary transfusion filters in the return line. The inclusion of the blood concentration technology will extend the collection to delivery time for processed blood by around 10 min. In effect, the incorporation of the cell concentration element of the technology results in a delay in the transfusion process, associated with the processing of the first unit of blood; thereafter the system will operate essentially as an autotransfusion system. The transfusion of processed, concentrated cells also permits the administration of foreign expanders in proportion to the volume of plasma extracted while maintaining patient packed cell volume. However, under less challenging, and perhaps more common conditions, the system may be operated with the cell concentration system as a standard autotransfusion system. We would recommend the use of a return line filter in all circumstances.

This was entirely a laboratory-based study. Although based on the development of a blood salvage and autotransfusion technology that has been delivered to the global clinical community

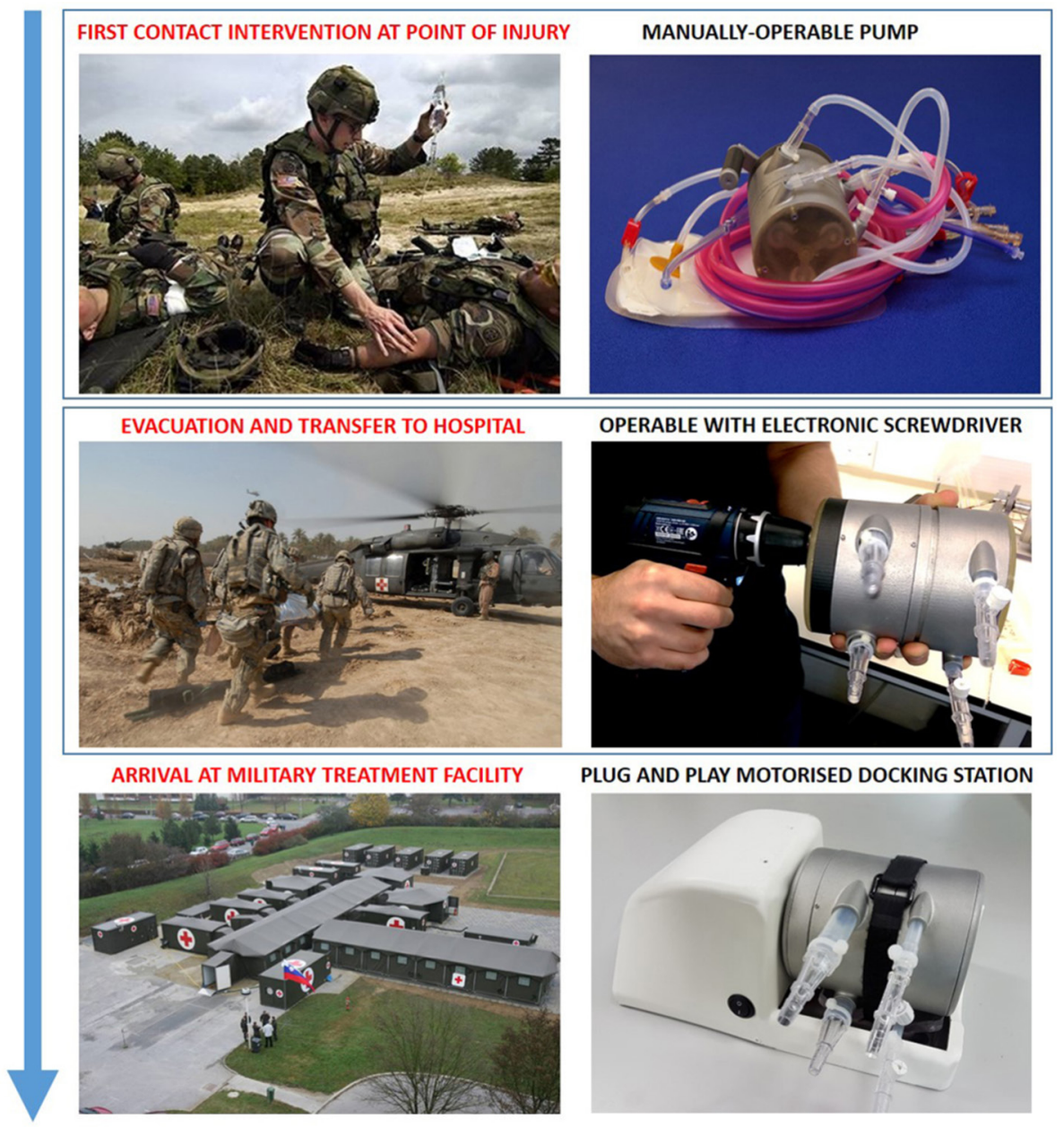

Figure 7 The technology was designed to treat—-through autotransfusion and cell concentration—-the casualty throughout the entire journey from the point of injury, during the evacuation and transfer to hospital stage and ultimately at arrival at a military treatment hospital. 
in partnership with our commercial partners Brightwake, we recognise that further work is required to determine its field deployability. Another limitation that needs to be addressed in relation to the development work is to assess the effectiveness of the technology under near-clinical conditions, in particular to test its effectiveness in a situation mimetic of major battlefield haemorrhage. It is conceivable that, under these conditions, additional blood isolation technologies will be required to enhance the effectiveness of the device. These issues will be addressed prior to field deployment trials that will form part of the regulatory approval process for the device. We recognise that there may be a need to increase the blood handling capabilities of the technology to cover the broad spectrum of lesions that the device may encounter in the field, but this will become apparent through the next stage of the device development process. However, it is clear that this technology as it stands has the capability to reduce the donor transfusion needs of injured personnel.

Contributors Professor TG: Conception and design of the work, and preparation of manuscript. Dr CS: Development and testing of the technology. Dr CR: Development, testing and preparation of manuscript

Funding This work was supported by the Ministry of Defence (Defence Science Technology Laboratory) Centre of Defence Enterprise Enduring Challenge (grant number CDE38281)

Competing interests None declared.

Provenance and peer review Not commissioned; externally peer reviewed.

Open Access This is an Open Access article distributed in accordance with the Creative Commons Attribution Non Commercial (CC BY-NC 4.0) license, which permits others to distribute, remix, adapt, build upon this work non-commercially, and license their derivative works on different terms, provided the original work is properly cited and the use is non-commercial. See: http://creativecommons.org/ licenses/by-nc/4.0/

(c) Article author(s) (or their employer(s) unless otherwise stated in the text of the article) 2018. All rights reserved. No commercial use is permitted unless otherwise expressly granted.

\section{REFERENCES}

1 Champion HR, Bellamy RF, Roberts CP, et al. A profile of combat injury. J Trauma 2003:54:513-19.

2 Holcomb J, Caruso J, McMullin N, et al. Causes of death in US special operations forces in the global war on terrorism: 2001-2004. US Army Med Dep J 2007:245:986-91.
3 Kelly JF, Ritenour AE, McLaughlin DF, et al. Injury severity and causes of death from operation Iraqi freedom and operation enduring freedom: 2003-2004 versus 2006. J Trauma 2008;64:S21-7

4 Eastridge BJ, Mabry RL, Seguin P, et al. Death on the battlefield (2001-2011): implications for the future of combat casualty care. J Trauma Acute Care Surg 2012;73(6 Suppl 5):\$431-7.

5 Eastridge B. Joint theater trauma registry data. (June 2006-November 2008), 2009

6 Niles SE, McLaughlin DF, Perkins JG, et al. Increased mortality associated with the early coagulopathy of trauma in combat casualties. J Trauma 2008;64:1459-65.

7 Cotton BA, Gunter OL, Isbell J, et al. Damage control hematology: the impact of a trauma exsanguination protocol on survival and blood product utilization. J Trauma 2008;64:1177-83.

8 Woolley T, Midwinter M, Spencer P, et al. Utility of interim ROTEM values of clot strength, $A 5$ and $A 10$, in predicting final assessment of coagulation status in severely injured battle patients. Injury 2013;44:593-9.

9 Brohi K, Singh J, Heron M, et al. Acute traumatic coagulopathy. J Trauma 2003:54:1127-30.

10 Borgman MA, Spinella PC, Perkins JG, et al. The ratio of blood products transfused affects mortality in patients receiving massive transfusions at a combat support hospital. J Trauma 2007;63:805-13.

11 Watts S, Nordmann G, Brohi K, et al. Evaluation of Prehospital Blood Products to Attenuate Acute Coagulopathy of Trauma in a Model of Severe Injury and Shock in Anesthetized Pigs. Shock 2015;44(Suppl 1):138-48.

12 Langan NR, Eckert M, Martin MJ. Changing patterns of in-hospital deaths following implementation of damage control resuscitation practices in US forward military treatment facilities. JAMA Surg 2014;149:904-12.

13 Spinella PC. Warm fresh whole blood transfusion for severe hemorrhage: U.S. military and potential civilian applications. Crit Care Med 2008:36:S340-5.

14 Lozano ML, Rivera J, Gónzález-Conejero R, et al. Loss of high-affinity thrombin receptors during platelet concentrate storage impairs the reactivity of platelets to thrombin. Transfusion 1997;37:368-75.

15 Manno CS, Hedberg KW, Kim HC, et al. Comparison of the hemostatic effects of fresh whole blood, stored whole blood, and components after open heart surgery in children. Blood 1991;77:930-6.

16 Kauvar DS, Holcomb JB, Norris GC, et al. Fresh whole blood transfusion: a controversial military practice. J Trauma 2006;61:181-4.

17 Department of the Army. Army regulation 40-8 medical services temporary flying restrictions due to exogenous factorsaffecting aircrew efficiency. Washington, DC Department of the Army, 16 May 2007.

18 Malone DL, Dunne J, Tracy JK, et al. Blood transfusion, independent of shock severity, is associated with worse outcome in trauma. J Trauma 2003:54:898-907.

19 Borden Institute US Army Medical Department Center and School Fort Sam Houston, Texas Office of The Surgeon General United States Army Falls Church, Virginia. Shock and Rescuscitation. In: Emergency war surgery: Third United States revision (2004): Library of Congress Cataloging, 2004:7.7.

20 Gunaydin S, Gourlay T. Novel ultrafiltration technique for blood conservation in cardiac operations. Ann Thorac Surg 2013:95:2148-51.

21 Gourlay T, Gunaydin S, 2013. Clinical outcome of transfusion processed by ultrafiltration in patientsundergoing coronary bypass. Abstracts of the 14th Annual NATA Symposium, Vienna, MA, Transfusion Medicine; April 18-19. 